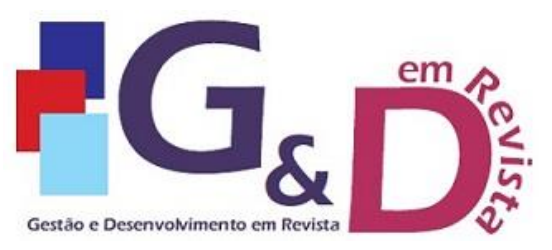

\title{
REFLEXÕES SOBRE O USO DO ECONOMIC VALUE ADDED NA GESTÃO ESTRATÉGICA DE UMA COOPERATIVA DE CRÉDITO
}

\author{
Tiago Luis Bruanera \\ Graduacão em Ciências Contábeis. Mestrado em Tecnologias e Gestão em Sustentabilidade pela \\ Universidade Estadual do Oeste do Paraná. Atualmente é professor de Contabilidade no Centro \\ Universitário Dinâmica das Cataratas. \\ E-mail: tiagobrugnera@gmail.com
}

\section{Cicera Rolim Antunes}

Graduação em Pedagogia pela Universidade Estadual do Oeste do Paraná e Graduação em Ciências Contábeis pelo Centro Universitário Dinâmica das Cataratas.

E-mail: rolimcicera@gmail.com

Renata Laoane Campaqnaro

Graduação em Ciências Contábeis pelo Centro Universitário Dinâmica das Cataratas .

E-mail: reecampagnaro@gmail.com

\section{Resumo}

No contexto globalizado do mercado, é razoável a adocão da premissa de que as empresas buscam resultados tanto financeiros como econômicos em um nível que os considerem satisfatórios de forma a viabilizar a remuneração dos investimentos realizados, neste sentido, os resultados vêm identificados por meio da aplicação de técnicas contábeis e econômicas, denominados indicadores de desempenho. Não obstante o resultado discreto, a metodologia do cálculo do EVA e sua análise fragmentada também fornecem informações potencialmente relevantes do ponto de vista de diagnóstico para reavaliação de planejamento estratégico de uma entidade. Por meio de pesquisa bibliográfica, abordagem qualitativa e provocações reflexivas, buscou-se realizar um estudo teórico de como o indicador de desempenho econômico Economic Value Added (EVA) auxiliaria na gestão organizacional estratégica de uma cooperativa de crédito. Como principais reflexões, o acompanhamento e indexação do NOPAT como metas de resultados setoriais implicaria em otimização de gestão estratégica, além de permitir uma comparabilidade equalizada entre outras cooperativas de crédito e instituições financeiras privadas do segundo setor da economia, além de que eventuais resultados negativos para o EVA possam indicar aos gestores em quais aspectos (rentabilidade acionária mínima ou ônus de terceiros) mais requerem reavaliação estratégica.

Palavras-Chave: Gestão Estratégica; Indicador de Desempenho; Economic Value Added

\begin{abstract}
In the globalized market context, it is reasonable to adopt the premise that companies seek both financial and economic results at a level that they consider satisfactory in order to make the return on investments made feasible. In this sense, the results have been identified through the application accounting and economic techniques, called performance indicators. Notwithstanding the discrete result, the EVA calculation methodology and its fragmented analysis also provide potentially diagnostic-relevant information for reevaluating an entity's strategic planning. Through bibliographic research, qualitative approach and reflexive provocations, we sought to conduct a theoretical study of how the Economic Value Added (EVA) economic performance indicator would assist in the strategic organizational management of a credit union. As main reflections, the monitoring and indexing of NOPAT as sectoral results targets would imply optimization of strategic management, as well as allowing equalized comparability between other credit unions and private financial institutions of the second sector of the economy, as well as any negative results for the sector. EVA can indicate to managers in which aspects (minimum shareholder return or third party burden) most require strategic revaluation.
\end{abstract}

Key-Words: Strategic management; Performance Indicator; Economic Value Added 


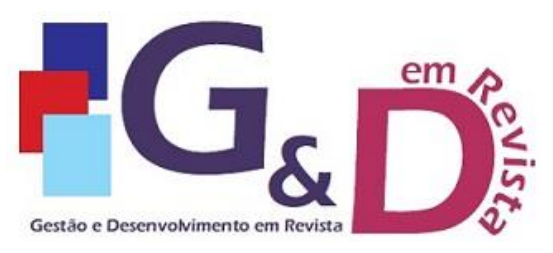

Gestão e Desenvolvimento em Revista V. 6, N. 1, jan-jun/2020, p. 15-27.

ISSN online: $2446-8738$

Artigo recebido em: 26/12/2019

Artigo aprovado em: 15/06/2020

\section{INTRODUÇÃO}

No contexto globalizado do mercado, é razoável a adoção da premissa de que as empresas buscam resultados tanto financeiros como econômicos em um nível que considerem satisfatório de forma a viabilizar a manutenção dos investimentos realizados, assim, a identificação de tais resultados advém, geralmente, da aplicação de técnicas contábeis e econômicas - os denominados indicadores de desempenho, técnicas que um gestor pode se utilizar para identificar e mensurar, de forma positiva ou negativa, os resultados provenientes das diversas atividades em curso em uma entidade. Dentre os indicadores que podem evidenciar de forma coadunada os resultados econômico-operacionais juntamente a diagnósticos de efetividade e reavaliação do planejamento estratégico de gestão, o Economic Value Added (EVA) destaca-se, possibilitando confrontar a rentabilidade de um investimento com o seu custo ponderado próprio e de terceiros, ou seja, o gestor da empresa tem a visão do impacto de suas decisões no futuro da sua empresa no que tange à criação de valor econômico e, por conseguinte, sua continuidade.

Não obstante as empresas não serem uníssonas na forma de serem geridas, as diferentes espécies de empresas afetam diretamente o modo de diagnosticar os resultados e planos em execução. As cooperativas de crédito, como exemplo, enquanto entidades categorizadas como "terceiro setor", assumem atividades do segundo setor econômico e não absorvem indicadores de rentabilidade e desempenho econômico da mesma forma que entidades financeiras tradicionais ou empresas limitadas comerciais.

Desde sua concepção, essas cooperativas vêm ganhando cada vez mais espaço e sócios em meio ao mercado financeiro com bancos comerciais tradicionais oferecendo os mesmos produtos e serviços, se diferenciando na filosofia corporativa de tratamento de seus cooperados em uma categoria além da clientela. Ainda assim, mesmo com um aumento progressivo de interessados e com a conquista de mais espaço no mercado, há um inerente aumento no foco por resultados, pois independente do foco da entidade, uma situação superavitária se faz fundamental para poder movimentar valores e poder atender seus associados da forma mais satisfatória. Sendo assim, a fim de oferecer o melhor aos seus cooperados, é requisito fundamental que sejam eficientes em sua gestão.

Não apenas as cooperativas de crédito, mas qualquer entidade que explore o capital, devem ter o ímpeto de buscar constantemente formas de melhorias e inovações dentro de seu negócio, principalmente com o avanço da tecnologia e as evoluções da demanda mercadológica, como exemplo, pode-se citar as instituições financeiras, que estão cada vez mais interessadas em apresentar a seus clientes formas mais fáceis e práticas de utilização de seus serviços por meio de aplicativos em dispositivos móveis que facilitam o cotidiano dos usuários, na expectativa de acrescer o nível de satisfação e o converter em manutenção da conta e fidelidade à entidade. Exemplos assim demonstram o quanto um planejamento estratégico funcional é necessário para a sobrevivência comercial de uma empresa, o que endossa a relevância de um efetivo acompanhamento diagnóstico do planejado.

Diante do exposto, considerando a importância do acompanhamento e planejamento estratégico de gestão atrelada a um efetivo indicador de desempenho econômico-financeiro das instituições, o trabalho propõe reflexões a seguinte pergunta: quais as contribuições e potenciais usos do Economic Value Added - EVA 
em uma gestão de uma cooperativa de crédito? Neste sentido, o objetivo do presente estudo é o de discutir a utilização do EVA e suas possíveis indicações como ferramenta de gestão e tomada de decisão. No ponto de vista profissional, o trabalho poderá ser utilizado como referência para empresas financeiras e cooperativas de crédito no assunto de gestão estratégica e benefícios do indicador EVA, o que, se utilizado, agrega chances de sucesso na continuidade, rentabilidade e benefícios indiretos às empresas e stakeholders interessados e/ou envolvido.

Para tanto, 0 presente trabalho caracteriza-se como uma pesquisa bibliográfica (ensaio teórico) e encontra-se estruturado em três seções, para além desta introdução, que segue com o desenvolvimento tangente à indicadores de desempenho com destaque ao EVA e noções de planejamento estratégico. A terceira seção trata-se das considerações finais seguido das referências.

\section{DESENVOLVIMENTO}

\subsection{COOPERATIVISMO}

Segundo Cenzi (2012, p.17), "o termo “cooperação" origina-se do verbo latino cooperari, uma junção de cum e operari, resultando no significado de operar juntamente a alguém, prestação de auxílio para um fim comum." Ou seja, cooperar é ajudar alguém com o mesmo propósito que o seu. Em 1889, foi criada a primeira cooperativa no Brasil, a Cooperativa Econômica dos Funcionários Públicos de Ouro Preto em Minas Gerais, logo após essa, foram criadas cooperativas de diversos ramos, com a influência de europeus e japoneses (PELEGRINI; SHIKI; SHIKI, 2015), mas foi em 1902, 30 anos depois da doutrina cooperativista, que surge no Brasil a primeira cooperativa de crédito. Pelegrini, Shiki e Shiki (2015), diz que a primeira cooperativa de crédito foi criada por um padre jesuíta no Rio Grande do Sul, mais precisamente na Nova Petrópolis. O padre suíço Theodore Amstad criou a primeira cooperativa de crédito, a Caixa Rural de Nova Petrópolis, ele iniciava o que seria paralelo ao cooperativismo agroindustrial, o crescente cooperativismo de crédito brasileiro.

O modelo da cooperativa de crédito se iniciou, junto às pequenas comunidades rurais ou vilas, fundamentadas na honestidade de suas cooperadas e suas atuações se davam a partir de pequenos produtores rurais, sem dar importância ao capital dos cooperados, pois o foco principal sempre foi ajudar os produtores rurais a investir em seus negócios. Os cooperados realizavam toda a movimentação financeira através de depósitos, nos quais recebiam uma pequena remuneração. Qualquer pessoa poderia depositar, e com as sobras apuradas, criava-se então com mais segurança reservas para momentos de incerteza na agricultura (PORTAL DO COOPERATIVISMO FINANCEIRO, 2019).

Esse segmento foi se desenvolvendo e crescendo, dentro do estado, abrindo outras filiais. Com o passar dos anos, esse modelo de cooperativa de crédito foi sendo levada a outros estados, disseminando suas características. Pagnussat (2004), diz que em 1980, já havia um número significante de cooperativas de crédito em funcionamento, porém ainda assim não expressava um número relevante para o mercado financeiro nacional, pois nos depósitos remunerados, eles não podiam captar com uma taxa normal de mercado e nem abrir postos de atendimento para compensar cheques na câmara de compensação, foi então nesse ano que houve uma estruturação do sistema, foi desenvolvido estatuto social e regimento interno 
para passarem a atender os associados. Mas foi em 1995, que as cooperativas tiveram uma conquista que ampliaria sua posição como instituição financeira, neste ano o Conselho Monetário Nacional editou a Resolução no 2.193, que permitiu a criação dos bancos cooperativos, de propriedade exclusiva das cooperativas, através dos bancos, as cooperativas passaram a ter acesso à compensação de cheques, e todos os outros produtos e serviços financeiros. Tudo isso possibilitou ao cooperativismo de crédito a desempenhar seu papel de forma independente e ter vantagens competitivas em relação ao sistema bancário convencional. Pois, foi através disso que hoje as cooperativas de crédito podem "competir" de frente com os bancos comerciais, oferecendo os mesmos produtos e serviços de um banco, porém com um diferencial, o foco principal é o associado e não o lucro.

Meinen, Domingues e Domingues (2002), mostram que nas cooperativas, não se busca o lucro, pois, o que excede, pela lei e segundo as diretrizes assembleares, é devolvido de forma direta ou indiretamente a quem gerou o lucro, reduzindo as tarifas e os juros pagos no período, ou seja, é viabilizada a atividade econômica de interesse em comum aos participantes. O autor ainda diz que, as cooperativas operam com encargos e tarifas menores das que são praticadas pelos bancos, isso faz com que os bancos comerciais, com o objetivo de conquistar ou até mesmo recuperar os clientes, façam um ajuste para baixo nos spread (se refere à diferença entre o preço de compra e venda de um investimento, por exemplo) de empréstimos e financiamentos. Ou seja, as cooperativas de crédito se inseriram no mercado e hoje oferecem os mesmos produtos e serviços de um banco, permitindo a ela competir diretamente com os bancos comerciais.

Segundo Schardong (2003), a Cooperativa de Crédito tem como a finalidade de estimular a captação de recursos financeiros para financiar as atividades econômicas dos cooperados, prestando serviços de natureza bancaria como a administração de suas poupanças e outro que por eles demandados.

\subsection{PLANEJAMENTO ESTRATÉGICO E INDICADORES DE DESEMPENHO}

Toda entidade formalizada sob a ótima empresarial, independente da espécie de pessoa jurídica adotada, possui como objetivo básico a continuidade de sua própria existência, aliado a um autofinanciamento sustentável que resulte em resultados positivos aos stakeholders. A gestão estratégica vem para as empresas no sentido de fomentar as atividades com prévio planejamento e um acompanhamento permanente dos resultados e o desempenho previsto. Costa (2007, p. 56) conceitua a gestão estratégica como "o processo sistemático, planejado, gerenciado, executado e acompanhado sob a liderança da alta administração da instituição, envolvendo e comprometendo todos os gerentes e colaboradores da organização", ou seja, a gestão estratégica se inicia na alta administração e envolvem os demais colaboradores da instituição, ela deve acontecer em conjunto com todos os envolvidos para que se possa colocar em prática.

Conforme Camargo e Dias (2003), a gestão estratégica é uma das áreas do meio da gestão de maior destaque e relevância atualmente. Sua importância se dá no fato de ser um conjunto de ações gerenciais que permitem os gestores de empresas mantê-las ao seu meio e no curso correto de desenvolvimento, fazendo que atinja seus objetivos e sua missão. Esse entendimento é ratificado por Tavares (2010) quando explica que a gestão estratégica busca atrelar em um só processo a 
implementação do planejamento estratégico, no qual visa garantir as mudanças da organização que são necessárias para elaboração e participação dos diversos níveis da organização, que estão envolvidos no processo decisório.

Para além da aplicação do sistema de crenças e controle, parte do planejamento estratégico está na opção estratégica, que é em qual foco a empresa será direcionada. Conhecidos por alguns autores como trilema estratégico, Costa (2007, p. 39), apresenta que existem três tópicos em que uma empresa deve decidir apenas um deles para o seguir à excelência em seu negócio, se concentrando e mantendo foco em apenas uma delas dentre as opções "(i) fornecimento de produtos ou serviços de ponta; (ii) busca da excelência operacional; ou (iii) estreitamento de seu relacionamento e de sua intimidade com os seus clientes". Segundo o autor, uma organização deve definir em qual dos três pontos deve voltar o seu foco, não podendo focar nos três ao mesmo tempo, pois se entende que não realizaria nenhum dos três com excelência.

As cooperativas de crédito, por sua vez, tem como foco principal o terceiro item, o estreitamento de seu relacionamento e de sua intimidade com os seus associados. Por esse motivo, as cooperativas buscam prezar pelo bom atendimento, trabalhando isto como um potencial diferencial das demais instituições financeiras. Ocorre que embora as entidades cooperativas (ou comerciais tradicionais) decidam por seguir um ou outro caminho, é o efeito resultante das ações tomadas que demonstram quais os acertos e ajustes necessários para o alcance efetivo do plano inicialmente proposto - é nesta problemática que os indicadores de desempenho possuem papel fundamental (LIZOTE et al, 2013).

Com a evolução contínua da ciência contábil, uma série de índices diferentes para avaliação econômico-financeira de uma entidade foram idealizados, cada qual com seu propósito específico, de forma que possuíssem valor informacional em análise independente, mas também que evidenciassem situações quando analisadas em conjunto com outras técnicas, tornando assim a análise das demonstrações contábeis uma das melhores técnicas para obtenção de índices econômicos e de desempenho organizacional.

Os diagnósticos empresariais podem ser realizados com base em ferramentas gerenciais especialmente desenvolvidas para diferentes momentos e conceitos a serem alcançados (SOUSA et al., 2018). Alguns exemplos de ferramentas de gestão, como o Balanced Scorecard, os diagramas de Pareto, de Nishikawa e de Kano, os próprios conceituais $5 \mathrm{~W} 2 \mathrm{H}$, os Seis Sgimas (metodologia Lean) organização por Canvas, e outros foram construídos como auxiliares na administração das entidades e planejamento estratégico das metas, objetivos e decisões mercadológicas e operacionais.

Outro cluster de indicadores, como citados por Brigham, Gapenski e Ehrhardt (2000) são os de efetivo diagnóstico situacional de cunho econômicofinanceiro, como as análises de Liquidez, graus e composição do endividamento, Rentabilidade (de ativos, de patrimônio e de investimentos), Payback empresarial, Capital Circulante Líquido e diagnósticos de efeito tesoura, estimativas de solvência de curto e longo prazo, valor mercadológico situacional e potencial da entidade (MV e MVA) e o valor econômico adicionado (EVA), este último, a ser tratado a seguir com mais detalhamento.

Segundo Soares (2014), o EVA tem por objetivo quantificar a criação de valor das empresas e tornou-se mais difundido com a patente da equação pela empresa americana Stern Stewart \& Co, empresa especializada em gestão baseada 
em valor, que tem o objetivo de criar valores e gerir as empresas para que tenham retorno financeiro, fundada em 1982 por Joel M. Stern e G. Bennett Stewart III, criadora dos conceitos EVA - Economic Value Added (Valor econômico adicionado) e WAl - Wealth Added Index (Índice de riqueza adicionado).

A definição de EVA pela empresa Stern Stewart \& Co $(2014$, p.10) é que "EVA é uma estimativa do lucro econômico real após subtrair o custo de oportunidade do capital empregado no negócio" e que "o objetivo do EVA é fazer com que os administradores pensem, ajam e sejam remunerados como se fossem acionistas", pois um acionista sempre espera que a empresa na qual esteja investido tenha retorno sobre o capital que ela investiu, e um administrador trabalhando na sua empresa agindo como um acionista buscará resultados promissores para que tenha retorno sobre o seu investimento. Por tal motivo, a Stern Stewart \& Co, mostra em sua apresentação um sistema de gestão que é seguido pelo EVA, no qual segue 4 pontos:

1. Medir a performance com base no resultado econômico de criação de valor e de riqueza para o acionista.

2. Redesenhar os sistemas de gestão de forma a permitir que os processos de planejamento estratégico, alocação de recursos e gestão de resultados tenham foco na criação de Valor.

3. Motivar os gestores a criar valor ao relacionar o sistema de remuneração à criação de valor.

4. Fortalecer a Cultura de Criação de Valor através de treinamento e comunicação, tornando os gestores mais conscientes do processo de criação de valor.

O EVA se diferencia dos demais indicadores por valorizar o custo do capital próprio, mostrando um lucro mais econômico que contábil de uma empresa. Soares (2014) define EVA como as receitas geradas pela empresa depois da dedução dos custos referentes ao seu funcionamento e capital investido, tendo o lucro real da empresa. Encontra-se o EVA, após a dedução de todos os custos e despesas gerados, permitindo que se obtenha a maior precisão dos lucros gerados pela empresa. Pode-se entender melhor sobre o EVA aplicado na gestão da empresa por meio das palavras de Mota et al. (2010, apud Soares, 2014, p. 26):

\begin{abstract}
O EVA constitui uma ferramenta de gestão extremamente importante. Ao confrontar a rentabilidade de um investimento com o seu verdadeiro custo, 0 gestor tem a noção clara do impacto das suas decisões no futuro da empresa, o que permite uma maior responsabilização. Desenvolve-se assim uma relação mais estreita entre o gestor e os acionistas que tende a consolidar-se se a remuneração deste estiver indexada ao EVA gerado, em que o gestor pensa e atua como se ele próprio fosse dono da empresa.
\end{abstract}

A partir desse indicador, e tendo conhecimento sobre ele, o gestor da empresa consegue entender sobre o impacto que será gerado sobre a rentabilidade do investimento. Davies (1996) esclarece também que o EVA permite que a administração da empresa obtenha o conhecimento exato se está criando ou destruindo a riqueza dos acionistas, pois qualquer projeto ou empreendimento deve render um resultado econômico que justifique a apuração de um EVA positivo, desta forma gerando um valor adicional para a empresa.

Para se calcular o EVA, é necessário que primeiramente o gestor esteja familiarizado com outros dois indicadores que compõem a metodologia para cálculo dele: O Net Operating Profit After Taxes - NOPAT (ou Lucro Operacional Líquido 
Após Impostos - LOLAl) e o Weighted Average Capital Cost - WACC (ou Custo Médio Ponderado de Capital - CMPC).

\subsection{NET OPERATING PROFIT AFTER TAXES - NOPAT}

Segundo Parisi e Megliorini (2011), o NOPAT é uma forma para se calcular o lucro gerado pelas operações da organização, medindo a produtividade do capital empregado, sem levar em conta os financiamentos feitos pela empresa, apresentando os lucros das atividades que a organização realiza, após a dedução dos impostos sobre tal resultado. Uma das formas mais simplificadas para sua identificação é a dedução do EBIT (Earnings Before Interests and Taxes) dos tributos sobre lucro com diferimento dos efeitos fiscais das despesas e receitas não operacionais. Segundo Silva (2003), o NOPAT é um conceito bem amplo, pois para - seu cálculo, considera-se a depreciação dos ativos imobilizados e os impostos incidentes sobre o resultado operacional.

Sendo assim, sua fórmula, conforme Parisi e Megliorini (2011) calculam o lucro gerado pelas operações da empresa, analisando a produtividade do capital, não levando em consideração os financiamentos realizados pela empresa mostrando dessa forma os lucros das atividades que a organização realiza, após a diminuição dos impostos de forma possa ser utilizado para, efetivamente, mensurar de forma padronizada e comparável diferentes entidades em diferentes países, cada qual com seu efeito e política fiscal própria.

Portanto, conforme Ehrbar (1999), os ajustes transformam lucros contábeis em econômicos, com isso, fazendo que o NOPAT descreva um valor econômico mais verdadeiro e o capital sendo avaliado de uma melhor maneira referente aos fundos de acionistas e credores, ou seja, é o resultado ponderado de variáveis operacionais como política de preços praticados, taxas cobradas, política de pessoal, custos e despesas de manutenção, reflexos de infraestrutura da rede e marketing. A gestão estratégica de uma cooperativa de crédito deve pautar-se pelo aumento do NOPAT primordialmente, vez que seu acréscimo traria benefícios a médio e longo prazo para a instituição, pois o aumento do NOPAT evidencia uma eficiência progressiva na gestão operacional da entidade e, consequentemente, um acúmulo de riquezas a confrontar com os custos necessários para sua realização.

Cabe apontar, também, que havendo um controle consistente e consciente do NOPAT, ele torna viável analisar causas e consequências (política de riscos e planos estratégicos extraordinários) do resultado líquido, sobretudo em relação ao resultado financeiro (variável dependente). De forma sintetizada, o NOPAT positivo evidencia uma política operacional vantajosa, a princípio, que confrontará com os custos necessários para sua manutenção com valores adicionados como resultado líquido.

\subsection{WEIGHTED AVERAGE CAPITAL COSTS - WACC}

O WACC, por sua vez, como mencionado, é o custo médio ponderado do capital, ou seja, determinar o custo total do capital investido, sendo de terceiros ou próprios, ambos ponderados em conjunto. Pode se representar o WACC, de forma generalizada, como a taxa mínima de retorno, ou seja, a atratividade econômica desejada pela organização em suas decisões de investimento. Se o retorno operacional não for igual ou superior ao WACC calculado, a empresa estará 
deixando de remunerar as fontes de capital próprio ou de terceiros, fazendo assim que prejudique o seu valor no mercado, explica Assaf Neto (2014). Portanto, um resultado menor que o WACC, mostra que a empresa não está sendo capaz de atender às expectativas dos financiadores do capital utilizado na empresa (próprios ou não), ocasionando assim um decréscimo de valor de mercado, sendo o inverso igualmente aplicável. Assim, o WACC pode ser calculado:

$\left(\mathrm{Kp}{ }^{*} \mathrm{CP} / \mathrm{A}\right)+\left[\left(\mathrm{Kt}{ }^{*} \mathrm{CT} / \mathrm{A}\right){ }^{*}\left(1-\mathrm{IR}^{*}\right)\right]$

Em que:

WACC: taxa de custo médio de renda ponderada do capital;

Kp: custo do capital próprio;

CP/A: proporção do capital próprio sobre o ativo total da empresa;

Kt: custo do capital de terceiros

CT/A: proporção do capital de terceiros sobre o ativo total da empresa;

IR: alíquota do imposto de renda e da contribuição social da pessoa jurídica.

O custo de capital de uma empresa é a remuneração mínima exigida pelos proprietários de suas fontes de recursos, que seriam os credores e acionistas. Para Gitman (2002), é a taxa de retorno que a empresa precisa ganhar através de seus investimentos, com isso mantendo o seu valor de mercado das suas ações. O WACC, sendo o custo médio ponderado de capital, auxilia na determinação dos custos totais do capital investido, sendo esses compostos de terceiros e próprios.

Assim, com o reconhecimento do WACC de uma cooperativa de crédito, pode-se identificar as taxas dos custos de capitais de terceiros e próprios, de forma segregada, tanto independentes quanto interdependentes, e o quanto a empresa apresenta atratividade de acordo com o retorno mínimo que o investimento deve obter no setor ora em tela. Em análise a esse indicador, é preciso identificar o custo de capital de terceiros, ou seja, o impacto que uma dívida com terceiros poderá representar no retorno do capital, assim como o capital próprio e o quanto do custo do próprio capital impacta no resultado (LUCENA et al, 2013).

A utilização de metas estratégicas com a redução do WACC sendo referencial permitiria, ao menos, tornar-se comparável com entidades bancárias tradicionais e com outras cooperativas de crédito, vez que tal indicador contempla direta e indiretamente a estrutura disponível e políticas de financiamento operacional e societário. O WACC é um custo ponderado volátil, pois depende diretamente da definição dos custos individuais dos stakeholders da operação de investimento. Assim, conforme abstrai-se também do estudo de Lucena et al (2013), podem-se analisar os seguintes pontos como críticos para análise:

a) Custo de oportunidade média em aceitação de associados: Em relação às cooperativas concorrentes, o retorno dos dividendos pode ser utilizado como critério de decisão de permanência nas cooperativas por parte dos associados, assim, o uso do ROE médio setorial se torna mais indicável, ou, ainda, torna-se visível a migração com base em uma escala concorrencial de taxas de retorno;

b) Custo do capital de terceiro oneroso: Considerando a realidade de instituições financeiras, taxas como SELIC, o spread bancário e outras métricas tornam-se acompanháveis pela cooperativa e comparável, assim, permite-se ajustar, de forma contínua, os planos estratégicos elaborados pela administração que sofram influência direta de tais custos. 
c) Custo do capital de terceiro não-oneroso: Divergindo do custo oneroso, a cooperativa possui viabilidade de levantar os custos de terceiros operacionais atrelados a eventuais fornecedores, tributos, salários, e outros passivos. Tal levantamento permite confrontar de forma mais exata um Grau de Alavancagem Financeiro - GAF voltado à operacionalidade da cooperativa, assim, influenciando diretamente o planejamento estratégico de momento mais oportuno (curto prazo, longo prazo, ou prazo indeterminado) de acrescer seu endividamento negativo (quando o rendimento do capital captado supera o custo do mesmo). Com a evidenciação do WACC, pode-se utilizar essa taxa de forma estratégica na instituição, pois reconhecendo o custo que a instituição terá em cada operação, auxiliará como uma base do quanto precisará "trabalhar" para aumentar seu lucro operacional, focando no resultado positivo do EVA.

d) Custo ponderado total da entidade: Como mencionado no decorrer do trabalho, o custo médio ponderado de capital apresenta o custo total investido, tanto dos custos de terceiros como o custo do capital próprio. A instituição prezando sobre o melhor controle dos custos totais do capital investido terá um melhor controle sobre quanto precisará obter de lucro operacional para que seu EVA seja positivo. Ou seja, obtendo a informação do custo ponderado total da entidade, a instituição de forma estratégica tem o valor dos custos que está ocorrendo internamente e externamente, sendo eles de terceiros ou de próprio e, a partir deste ponto estabelecer estratégias de redução e/ou controle para que os custos sejam menores que o lucro operacional.

Como exemplo, pode-se citar a análise progressiva e comparativa dos custos de terceiros. São variáveis dependentes da análise o tamanho do Capital de Terceiros (Passivo total menos o Patrimônio Líquido) e uma taxa ponderada desonerável de tributos sobre lucro. Políticas de prazos médios de pagamento de contas (como o PMPF na contabilidade gerencial), estudos de Ciclos de Caixa (Ciclo Operacional da entidade menos o PMPF) e rebalanceamento da Composição do Endividamento (Passivo Circulante dividido pelo Capital de Terceiros) são três exemplos de indicadores que afetam indiretamente a Taxa de Custo de Capital Externo, que influencia diretamente o montante discreto a ser analisado (GITMAN, 2002). Um planejamento eficiente nestes três indicadores pode acarretar uma redução geometricamente progressiva nos custos ponderados totais $e$, consequentemente, um valor econômico agregado mais positivo.

A vantagem de se ter esse controle, conforme sugere Gitman (2002), é uma melhor administração dos valores, pois como exemplo a cooperativa de crédito com a abertura de novas agências, é comum que seu custo seja superior ao seu lucro operacional entre os primeiros anos de abertura da agência, com isso não se vislumbra um lucro suficiente para a distribuição de sobras. Utilizando a informação do custo médio ponderado total, pode-se adotar estratégias como, por exemplo, avaliar se o custo da construção de uma sede própria é mais viável que alugar um prédio pronto, até que a agência possa ter retorno o suficiente para a construção ou compra de um prédio e ainda assim obter um lucro que possa resultar ainda na distribuição de sobra para os associados e colaboradores.

\subsection{ECONOMIC VALUE ADDED - EVA}

Assim, com tais conceitos explorados, a metodologia do cálculo do EVA torna-se mais lógica. Segundo Crepaldi (2008) o EVA é considerado por muitos 
como a forma mais perfeita de medir a performance econômica em determinado período, traduzindo os resultados verificados numa óptica contábil numa realidade econômica. Por tal motivo, o gestor tendo conhecimento dos indicadores econômicos, ao realizar o acompanhamento do EVA em sua gestão, poderá contar com um auxílio diagnóstico no desempenho da sua empresa, pois como Crepaldi (2008, p. 287) cita, "o EVA tem a grande vantagem de ser um indicador conceitualmente simples e fácil de compreender, pelo menos ligadas a finanças, uma vez que se resume a uma relação entre resultado operacional e o custo do capital investido." A equação para cálculo do EVA é a abaixo indicada:

$$
E V A=N O P A T-\left(W A C C^{*} K\right)
$$

EVA: Valor Econômico Agregado;

NOPAT: Lucro Operacional Liquido após os impostos;

WACC: Custo Médio Ponderado de capital;

$\mathrm{K}$ : Capital Investido.

Soares (2014) indica que se o resultado da análise do EVA for positivo, entende-se que a empresa está criando valor, independente do resultado líquido contábil que não precisa ser necessariamente positivo, e a empresa poderá ter lucro mesmo depois de serem considerados os custos do capital investido. Caso seja negativo o resultado, significa que a rentabilidade do investimento é menor ao custo médio ponderado a utilização do capital, e a empresa terá custos por investir no capital que não irá gerar criação de valor.

O autor, ainda sugere que para aumentar o EVA, é necessário adotar algumas estratégias, como (i) Aumentar a rentabilidade do capital de que dispõe sem efetuar novos investimentos; (ii) Diminuir o custo do capital, devido a uma gestão mais eficiente, ou devido a fatores externos a própria empresa; (iii) Investir em outros projetos com uma rentabilidade superior ao custo do capital que empregam; (iv) Desinvestindo, reduzindo total ou parcialmente o capital aplicado em investimentos cuja rentabilidade não permite remunerar o capital que empregam; e (v) Aumentar o horizonte temporal durante o qual a empresa vai manter a vantagem competitiva que lhe permite que a rentabilidade seja superior ao custo do capital. De uso dessas estratégias sugeridas pelo autor, pode-se buscar um diferencial para se obter um resultado positivo no EVA, e gerar criação de valor para a empresa.

A título de ilustração para melhor compreensão, caso se considere um resultado de EVA positivo mas com um valor baixo em relação no NOPAT (inferior a $1 \%$, como exemplo) pode-se perceber que os custos de capital (incluindo satisfação de terceiros e de cooperados, economicamente falando) que a instituição obteve foram inferiores ao resultado operacional alcançado, a ponto de gerar um resultado de EVA positivo, porém, ainda alto o suficiente para que não demonstre retorno econômico relevante, ou seja, não está gerando uma criação de valor evidentemente significante para a instituição, ainda que não esteja consumindo riqueza para sua manutenção mínima.

Situação esta divergente de um caso de um resultado de EVA em valor maior, como, por exemplo, um valor relativo de $15 \%$ ou mais do NOPAT, onde podese perceber uma sobreposição significativa entre o resultado operacional positivo e o custo econômico de seu financiamento (análise independente), e a partir disso é possível considerar que os investimentos realizados pela instituição (nos critérios 
estrategicamente definidos e acordados com terceiros e próprios) estão trazendo retornos e gerando criação de valor (análise interdependente), ou seja, a partir dessa análise pode-se afirmar que a instituição estaria tendo um desempenho financeiro positivo, que traz resultados favoráveis para a instituição de forma significativa - uma adição econômica significativa à cooperativa.

O raciocínio também se aplica caso o EVA apresentasse um resultado negativo, como, por exemplo, um valor relativo de $-5,00 \%$ (cinco por cento negativo) é possível afirmar que a instituição não está tendo criação de valor, mas pelo contrário, está ocasionando destruição de valor onde os custos de seus investimentos e financiamentos estão superando o lucro operacional. Observando a fórmula, pode-se dizer que o valor do NOPAT é inferior ao valor do WACC aplicado ao seu ativo e esses resultados despertam uma atenção para quem pretende investir na empresa em questão. Sobretudo quando o EVA encontra-se negativo, como no exemplo acima, cabe algumas análises pontuais por parte da cooperativa de crédito ora interessada:

1) Se a destruição de valor encontra-se no NOPAT insuficiente, a cooperativa deve urgentemente reanalisar as causas do mesmo. Para tanto, diversas ferramentas diagnósticas podem ser utilizadas, como o Balanced Scorecard, o Diagrama de Pareto, o diagrama de Ishikawa ou até os próprios ciclos PDCA e 5W2H podem ser úteis. Assim, a cooperativa possuirá a compreensão de que embora possua um NOPAT eventualmente positivo, o mesmo necessita de um crescimento para tornar o empreendimento sustentável economicamente;

2) Se a destruição de valor encontra-se no WACC, mas especificamente na parte de custo de terceiros, cabe à cooperativa reanalisar sua política financeira e sistemas de gerenciamento de terceiros. Análises como as pertinentes aos ciclos operacionais e de caixa (Prazos Médios Gerenciais, Ciclos de autofinanciamento e outros), as de troca de fornecedores menos onerosos (como gestão terceirizada de algumas áreas ou exploração de intechs em gestão de capital), ou até uma reanálise de política interna de balanço do Grau de Alavancagem Financeira (GAF) podem contribuir para uma redução do custo e promoção do EVA;

3) Se a destruição de valor encontra-se no WACC, mas especificamente na parte de custo de capital próprio, cabe à cooperativa reanalisar as expectativas de rentabilidade mínima e riscos atrelados à captação de investimentos, sobretudo nos indicadores de ROE; e

4) Se a destruição de valor não se encontra no NOPAT, no WACC de terceiros e nem no WACC próprio, cabe a reflexão por parte da cooperativa do investimento total existente em seu Ativo, de forma que é possível que o resultado operacional que a entidade possua não seja suficientes para suportar uma infraestrutura maior que a mesma faz jus, como uma ampliação superestimada de novas agências, como exemplo.

\section{CONSIDERAÇÕES FINAIS}

O presente trabalho trata-se da importância de utilizar o indicador de desempenho EVA de forma estratégica em uma cooperativa de crédito. O EVA é um indicador econômico que segundo alguns autores é o indicador mais preciso para se medir rentabilidade, além disso, é um indicativo de gestão, no qual pode-se confrontar a rentabilidade de um investimento com o seu custo ponderado próprio e de terceiros, ou seja, o gestor da empresa tem a visão do impacto de suas decisões 
no futuro da sua empresa no que tangem à criação de valor econômico e, por conseguinte, sua continuidade. No decorrer do trabalho se apresentam diversos indicadores de desempenho com seus conceitos e formas de aplicação. Foi utilizada como metodologia a pesquisa descritiva e explicativa, com abordagem qualitativa, sendo o método indutivo e a abordagem utilizada foi a bibliográfica documental.

Como principais resultados, pode-se concluir que a utilização do EVA de forma estratégica em uma cooperativa de crédito, trará como benefícios a instituição uma forma de ponderar o retorno que está tendo, se tratando de criação de valor, e, além disso, como ela poderá administrar estrategicamente a redução dos custos de capitais de próprios e de terceiros e/ou um aumento do lucro operacional para que consequentemente se tenha um EVA positivo, trazendo rentabilidades tanto para os administradores da instituição como para os associados de uma cooperativa de crédito.

Como limitações da pesquisa, indica-se a dificuldade de ampliar a discussão com um cálculo do EVA em uma cooperativa de crédito real, pois nas demonstrações publicadas, não foi possível localizar o custo de capital próprio e de terceiros para obter o valor do WACC, assim como a demonstração de resultado das instituições financeiras se difere de uma demonstração de resultado de empresa, houve a dificuldade de calcular também o NOPAT. Por tal motivo, sugere-se como estudos futuros a aplicação do método aqui discutido e proposto qualitativamente em uma abordagem quantitativa de forma a testar as hipóteses trabalhadas neste estudo.

\section{REFERÊNCIAS}

BRIGHAM, E. F; GAPENSKI, L. C.;EHRHARDT, M. C.. Administração Financeira: Teoria e Prática. São Paulo: Atlas. 2000.

CAMARGO, A.M.; DIAS, T.A. Estratégia, Administração Estratégica e Estratégia Corporativa: Uma síntese teórica. 2003. Disponível em: <http://www.geocities.ws/occfi/estrategia.pdf> acessado em: 26 de maio de 2019.

CENZI, Nerii Luiz. Cooperativismo: desde as origens ao Projeto de Lei de Reforma do Sistema Cooperativo Brasileiro. $1^{\underline{a}}$ ed. (ano 2009), $2^{\underline{a}}$ reimpr. Curitiba: Juruá, 2012.

COSTA, Eliezer Arantes da. Gestão Estratégica: da empresa que temos para a empresa que queremos. 2. Ed. São Paulo: Saraiva, 2007.

CREPALDI, S. A. Contabilidade gerencial: teoria e prática. 4. ed. São Paulo: Atlas, 2008.

DAVIES, Erin M. Como fazer os acionistas mais ricos usando o EVA. Revista Fortune, 1996.

EHRBAR, Al. EVA: valor econômico agregado: a verdadeira chave para a criação de riqueza. Rio de Janeiro, RJ: Qualitymark, 1999. xxii, p.183. 
GITMAN, Lawrence J. Princípios de administração financeira. 7.ed. São Paulo: Harbra, 2002.

LIZOTE, Suzete Antonieta et al. ANÁLISE DE VARIÁVEIS DE RELACIONAMENTO EM COOPERADOS: um estudo exploratório com associados a cooperativas de crédito. SEGET Simpósio de Excelência em Gestão da Tecnologia, 2013.

LUCENA, Edzana Roberta Ferreira da Cunha Vieira et al. Custo médio ponderado de capital: um estudo dos erros contidos em seu cálculo nas ofertas públicas de aquisições de ações registradas na comissão de valores mobiliários (CVM). ReCont: Registro Contábil, Maceió, v. 4, n. 1, p. 19-32, jan./abr., 2013. ISSN 2179-734X.

MEINEN, Ênio; DOMINGUES, Jeferson Nercolini; DOMINGUES, Jane Aparecida Stefanes (Org.). Cooperativas de crédito no direito brasileiro. Porto Alegre: Sagra Luzzatto, 2002.

PAGNUSSATT, Alcenor. Guia do cooperativismo de crédito - organização governança e políticas corporativas. - Porto Alegre: Editora Sagra Luzzatto, 2004.

PARISI, C.; MEGLIORINI, E. (Org.) Contabilidade Gerencial. São Paulo: Atlas, 2011.

Portal do Cooperativismo Financeiro. 2019. <https://cooperativismodecredito. coop.br/ cooperativismo/historia-do-cooperativismo/historia-no-brasil/> Acessado em: 27 de Abril de 2019.

PELEGRINI, Djalma Ferreira; SHIIKI, Simone de Faria Narciso; SHIKI, Shigeo. Uma abordagem teórica sobre cooperativismo e associativismo no Brasil. Extensio: Revista Eletrônica de Extensão, v. 12, n. 19, p. 70-85, 2015.

SCHARDONG, Ademar. Cooperativa de Crédito: Instrumento de Organização Econômica da Sociedade. 2.ed. Porto Alegre: Rigel, 2003.

SILVA, J. P. Análise financeira das empresas. São Paulo: Atlas, 2003.

SOARES, Ana Catarina Pereira. EVA (Economic Value Added) VS Indicadores Financeiros Tradicionais. Universidade de Coimbra. Coimbra, 2014.

SOUSA, Diego Camilo Ferreira et al. Utilização de ferramentas gerenciais para o controle de estoques: Um estudo de caso de uma empresa do setor alimentício. GESTÃO. Org, v. 15, n. 2, p. 546-563. 2017.

STERN STEWART \& CO. Ferramentas de Avalição. Fórum de Debates. Instituto Brasileiro de Governança Corporativa. 2014. Disponível em: http://docplayer.com.br/5035041-Forum-de-debates-geracao-de-valor-ferramentasde-avaliacao.html. Acesso em 18 ago. 2020.

Tavares, Mauro Calixta. Gestão estratégica. 3. ed. São Paulo: Atlas, 2010. 